\title{
Erratum to: Improving Gas Chromatography-Mass \\ Spectrometry Analysis of Essential Oils by Multivariate Curve \\ Resolution: Full Identification of Co-eluting Compounds \\ of Dracocephalum moldavica $\mathrm{L}$.
}

Fateme Tajabadi $^{1} \cdot$ Farahnaz Khalighi-Sigaroodi $^{1} \cdot$ Shamsali Rezazadeh $^{1}$

Published online: 13 July 2017

(C) Springer-Verlag GmbH Germany 2017

Erratum to: Chromatographia (2017) 80:1069-1077

DOI 10.1007/s10337-017-3322-2

The authors would like to call the reader's attention to the fact that unfortunately the authors' affiliation was wrong in the published article. The correct affiliation is:

(1) Medicinal Plants Research Center, Institute of Medicinal Plants, ACECR, Karaj, Iran

The online version of the original article can be found under doi:10.1007/s10337-017-3322-2.

Fateme Tajabadi

tajabadi@imp.ac.ir

1 Medicinal Plants Research Center, Institute of Medicinal

Plants, ACECR, Karaj, Iran 